\title{
ASO Editorial: Nodal Status as a Clinical Tool in the Treatment of Pancreatic Cancer
}

\author{
Marianna V. Papageorge, $\mathrm{MD}^{1}$, and Teviah E. Sachs, MD, $\mathrm{MPH}^{2}$ \\ ${ }^{1}$ Department of Surgery, Boston Medical Center, Boston University School of Medicine, Boston, MA; ${ }^{2}$ Department of \\ Surgery, Surgical Oncology, Boston Medical Center, Boston University School of Medicine, Boston, MA
}

Yamada and colleagues are to be congratulated for their study that explores the clinical implications of pathologically node-negative pancreatic cancer. ${ }^{1}$ Using a retrospective cohort design, the authors evaluated pancreatic cancer patients who underwent surgical resection (2002-2018), with lymph node dissection equal to or more than that recommended by the International Study Group on Pancreatic Surgery (ISGPS).

The authors' data confirm that patients with $\mathrm{pN} 0$ disease have higher 5-year survival rates than those with $\mathrm{pN} 1-2$ disease $(57.1 \%$ vs $25.0 \%)$. However, they were able to identify six prognostic factors for poor survival associated with pNO disease, specifically age of 70 years or older, non-administration of adjuvant chemotherapy, nerve plexus invasion, anterior serosal invasion, and microscopic lymphatic and venous invasion. In their study, the patients with an increasing number of prognostic factors had lower 5-year survival rates (90\% for 1 factor, $0 \%$ for 6 factors), and those with four or more risk factors had a survival similar to that for patients with pN1-2 disease.

The value of nodal status has been well-established as a predictor of outcomes in pancreatic cancer. ${ }^{2}$ The eighth edition of the American Joint Committee on Cancer (AJCC) recently revised its nodal definition to include $\mathrm{pN} 0$, pN1 (1-3 positive nodes), and $\mathrm{pN} 2$ ( $\geq 4$ positive nodes), representing the subtle staging difference based on nodal

(C) Society of Surgical Oncology 2021

First Received: 4 December 2020

Accepted: 19 December 2020;

Published Online: 16 January 2021

T. E. Sachs, MD, MPH

e-mail: Teviah.sachs@bmc.org disease. ${ }^{3}$ However, as the authors correctly state, evidence for the clinical value of $\mathrm{pNO}$ disease compared with pN1-2 disease is proportionally sparse.

Of the six prognostic factors the authors identified as indicating high risk, anterior serosal invasion and microscopic lymphatic invasion were found to be of particular interest. Indeed, these factors are not as well-documented in the literature. It would be interesting to know which specific factors, individually or in combination, result in worse outcomes. This study makes it apparent that the survival benefit associated with pNO does not apply equally to all patients.

It is particularly useful to view the authors' work in the context of adjuvant therapy. Although survival with pancreatic cancer has not progressed as far as with other cancers during the past 40 years, findings have made it clear that the use of adjuvant therapy improves survival and time to recurrence. ${ }^{4,5}$ Unfortunately, not all patients complete or even receive the recommended adjuvant therapy. ${ }^{6}$ It would be interesting, therefore, to expand upon the findings of this study to help determine the patients for whom adjuvant therapy would be most effective. The authors demonstrated that for patients with more than four risk factors, negative nodal status did not improve survival, which may have been due to more aggressive biology of the tumor or the presence of unidentified micro-metastases. $^{7}$ However, for the patients with few to no risk factors, the survival advantage was striking. Could it be, then, that $\mathrm{pN} 0$ patients with a greater number risk factors should be treated more aggressively in the adjuvant setting?

Notably, this study did not include patients who underwent neoadjuvant therapy, which is becoming more dominant in the treatment of pancreatic adenocarcinoma in the United States and elsewhere. ${ }^{8}$ The evidence clearly 
shows a survival benefit with neoadjuvant therapy, as well as a perceived selection benefit. ${ }^{9}$ It would be interesting to have the authors apply their risk-scoring to these patients to see whether the test of time that neoadjuvant therapy provides leads to fewer pNO patients with high risk factor scores due to improved patient selection.

In addition, the authors found that their preoperative diagnostic assessment had reasonable specificity and a positive predictive value (PPV), but less impressive sensitivity and a poor negative predictive value (NPV) (this is not surprising, as any pancreatic surgeon will attest). We are curious to see whether the NPV of the authors' preoperative diagnostic analysis would improve with neoadjuvant therapy, from either improved patient selection ordownstaging of chemo-sensitive tumors. The poor NPV and accuracy described by the authors also suggests a role for diagnostic laparoscopy in the preoperative workup of these patients, which we use and the literature supports. ${ }^{10,11}$

The appropriate methodology and reporting of lymph nodes is another subject of interest, and although not addressed in this study, the involvement of more distant lymph node stations may portend worse survival. ${ }^{12}$ This could be another interesting target for the authors' risk factor assessment.

The treatment of pancreatic cancer is highly dependent on tumor biology and staging. One key conclusion of this study was that $\mathrm{pN} 0$ does not guarantee long-term survival, but when used in combination with other risk factors that reflect tumor biology, it can be a very effective tool in the care we give to these patients. Although the removal of lymph nodes alone is not necessarily beneficial to the patient, it certainly aids clinicians and their patients in the discussion of expectations and prognosis, as well as in the planning of treatment.

\section{REFERENCES}

1. Yamada M, Sugiura T, Okamura Y, Ito T, Tamamoto Y, Ashida R, et al. Clinical implication of node-negative resectable pancreatic cancer. Ann Surg Oncol. 2020. https://doi.org/10.1245/s10434-02 0-09543-x

2. Lim JE, Chien MW, Earle CC. Prognostic factors following curative resection for pancreatic adenocarcinoma: a populationbased, linked database analysis of 396 patients. Ann Surg. 2003;237:74-85.

3. Kakar S, Pawlik TM, Allen PJ, et al. AJCC Cancer Staging Manual. 8th ed. Springer-Verlag, New York, NY, 2017.

4. Oettle H, Post S, Neuhaus P, Gellert K, Langrehr J, Ridwelski K, et al.. Adjuvant chemotherapy with gemcitabine vs observation in patients undergoing curative-intent resection of pancreatic cancer: a randomized controlled trial. JAMA. 2007;297:267-77.

5. Conroy T, Hammel P, Hebbar M, Ben Abdelghani M, Wei AC, Raoul JL, et al; Canadian Cancer Trials Group and the UnicancerGI-PRODIGE Group. FOLFIRINOX or gemcitabine as adjuvant therapy for pancreatic cancer. $N$ Engl $J$ Med. 2018;379:2395-406.

6. DePeralta DK, Ogami T, Zhou JM, Schell MJ, Powers BD, Hodul $\mathrm{PJ}$, et al. Completion of adjuvant therapy in patients with resected pancreatic cancer. HPB Oxford. 2020;22:241-8.

7. Takao S, Kurahara H, Maeda S, Shinchi $H$. The prognostic value of micrometastases in pancreatic cancer. Surg Oncol. 2008;17:195-202.

8. Gemenetzis G, Groot VP, Blair AB, Laheru DA, Zheng L, Narang AK, et al. Survival in locally advanced pancreatic cancer after neoadjuvant therapy and surgical resection. Ann Surg. 2019;270:340-7.

9. Gillen S, Schuster T, Meyer Zum Büschenfelde C, Friess H, Kleeff J. Preoperative/neoadjuvant therapy in pancreatic cancer: a systematic review and meta-analysis of response and resection percentages. PLoS Med. 2010;7:e1000267.

10. Allen VB, Gurusamy KS, Takwoingi Y, Kalia A, Davidson BR. Diagnostic accuracy of laparoscopy following computed tomography $(\mathrm{CT})$ scanning for assessing the resectability with curative intent in pancreatic and periampullary cancer. Cochrane Database Syst Rev. 2016;7:CD009323.

11. Paracha M, van Orden K, Patts G, Tseng J, McAneny D, Sachs T. Opportunity lost? Diagnostic laparoscopy in patients with pancreatic cancer in the National Surgical Quality Improvement Program Database. World J Surg. 2019; 43:937-43.

12. He C, Mao Y, Wang J, et al. Surgical management of periampullary adenocarcinoma: defining an optimal prognostic lymph node stratification schema. J Cancer. 2018;9:1667-79.

Publisher's Note Springer Nature remains neutral with regard to jurisdictional claims in published maps and institutional affiliations. 